\title{
Impaired growth and intracranial calcifications in autosomal dominant hypocalcemia caused by a GNA11 mutation
}

\author{
Sirpa Tenhola ${ }^{1,2}$, Raimo Voutilainen², Monica Reyes ${ }^{3}$, Sanna Toiviainen-Salo4, \\ Harald Jüppner ${ }^{3}$ and Outi Mäkitie ${ }^{5,6,7}$ \\ 1Department of Pediatrics, Kymenlaakso Central Hospital, Kotka, Finland, ${ }^{2}$ Department of Pediatrics, \\ Kuopio University Hospital and University of Eastern Finland, Kuopio, Finland, ${ }^{3}$ Endocrine Unit, \\ Massachusetts General Hospital and Harvard Medical School, Boston, Massachusetts, USA, ${ }^{4}$ Department \\ of Radiology, HUS Medical Imaging Center, University of Helsinki and Helsinki University Hospital, \\ Helsinki, Finland, ${ }^{5}$ Children's Hospital, University of Helsinki and Helsinki University Hospital, Helsinki, \\ Finland, ${ }^{6}$ Folkhälsan Institute of Genetics, Helsinki, Finland, and ${ }^{7}$ Department of Molecular Medicine \\ and Surgery, Karolinska Institutet and Department of Clinical Genetics, Karolinska University Hospital, \\ Stockholm, Sweden
}

Correspondence should be addressed to O Mäkitie

Email

outi.makitie@helsinki.fi

\begin{abstract}
Objective: Autosomal dominant hypocalcemia (ADH) is characterized by hypocalcemia and inappropriately low PTH concentrations. ADH type 1 is caused by activating mutations in the calcium-sensing receptor (CASR), a G-proteincoupled receptor signaling through $\alpha_{11}\left(G \alpha_{11}\right)$ and $\alpha_{q}\left(G \alpha_{q}\right)$ subunits. Heterozygous activating mutations in GNA11, the gene encoding $\mathrm{G} \alpha_{11}$, underlie ADH type 2. This study describes disease characteristics in a family with ADH caused by a gain-of-function mutation in GNA11.

Design: A three-generation family with seven members (3 adults, 4 children) presenting with ADH.

Methods: Biochemical parameters of calcium metabolism, clinical, genetic and brain imaging findings were analyzed. Results: Sanger sequencing revealed a heterozygous GNA11 missense mutation (c.1018G>A, p.V340M) in all seven hypocalcemic subjects, but not in the healthy family members $(n=4)$. The adult patients showed clinical symptoms of hypocalcemia, while the children were asymptomatic. Plasma ionized calcium ranged from 0.95 to $1.14 \mathrm{mmol} / \mathrm{L}$, yet plasma PTH was inappropriately low for the degree of hypocalcemia. Serum 25OHD was normal. Despite hypocalcemia $1,25(\mathrm{OH})_{2} \mathrm{D}$ and urinary calcium excretion were inappropriately in the reference range. None of the patients had nephrocalcinosis. Two adults and one child (of the two MRI scanned children) had distinct intracranial calcifications. All affected subjects had short stature (height s.D. scores ranging from -3.4 to -2.3 vs -0.5 in the unaffected children). Conclusions: The identified GNA11 mutation results in biochemical abnormalities typical for ADH. Additional features, including short stature and early intracranial calcifications, cosegregated with the mutation. These findings may indicate a wider role for $\mathrm{G} \alpha_{11}$ signaling besides calcium regulation.

\section{Introduction}

The calcium-sensing receptor (CASR) is a G-proteincoupled receptor expressed predominantly in the parathyroid glands and kidneys. It plays a central role in calcium homeostasis. Elevation in extracellular calcium activates CASR by signaling through the G-protein subunits $\alpha_{11}\left(\mathrm{G} \alpha_{11}\right)$ and $\alpha_{\mathrm{q}}\left(\mathrm{G} \alpha_{\mathrm{q}}\right)$. Activation of the CASRcoupled signaling pathway reduces PTH secretion and increases renal calcium excretion $(1,2)$.

Genetic abnormalities associating with CASR and its downstream signaling may lead to hyper- or www.eje-online.org DOI: 10.1530/EJE-16-0109
() 2016 European Society of Endocrinology Printed in Great Britain
Published by Bioscientifica Ltd. 
hypocalcemic disorders. Familial hypocalciuric hypercalcemia $(\mathrm{FHH})$ is an autosomal dominant disorder with genetically heterogenous subtypes. About two-thirds of $\mathrm{FHH}$ cases are caused by heterozygous loss-of-function mutations in the CASR gene on chromosome 3q21.1 leading to FHH type 1 (3). Heterozygous mutations in the GNA11 gene (on chromosome 19p13.3) encoding $\mathrm{G} \alpha_{11}$ may lead to lossof-function for this signaling protein and underlie FHH type 2 (4). Furthermore, mutations in the gene (on chromosome 19q13.3) encoding adaptor protein-2 $\sigma$ subunit (AP2S1), which regulates CASR signaling, cause FHH type $3(5,6)$. In contrast, heterozygous gain-of-function mutations in the CASR gene cause autosomal dominant hypocalcemia (ADH), defined as ADH type 1 (ADH1), as first described by Pollak et al. in 1994 (7). Recently, we (8) and others (4) identified four different heterozygous missense mutations in GNA11 in patients affected by $\mathrm{ADH}$ in whom CASR mutations could not be identified. The clinical hypocalcemic disorder caused by activating GNA11 mutations has been designated as ADH type 2 (ADH2). Until now, no gain-of-function mutations of AP2S1 with ADH have been described $(9,10)$.

ADH1 caused by CASR mutations is characterized by hypocalcemia, hyperphosphatemia, and serum PTH levels that are inappropriately low for the hypocalcemia (7). About $50 \%$ of $\mathrm{ADH} 1$ patients have mild or asymptomatic hypocalcemia; the symptoms include paresthesias, carpopedal spasms and seizures. Hypercalciuria with nephrocalcinosis or kidney stones was observed in about 10\%, and basal ganglia calcifications in more than $35 \%$ of the affected individuals $(1,4,11)$. Thim et al. reported that $25 \%$ of pediatric ADH1 patients were asymptomatic, 19\% had mild symptoms (carpopedal spasms, muscle cramps, paresthesias or neuromuscular irritability) and 56\% had severe symptoms (seizures) (12). Recent studies have revealed some differences between clinical features of ADH1 and ADH2. The ADH2 subjects lacked hypercalciuria more frequently than the ADH1 subjects $(4,13)$. Furthermore, Li et al. reported that subjects with ADH2 were significantly shorter than their unaffected relatives suggesting that GNA11 has a role in skeletal growth (13).

The number of reported subjects with ADH2 is still very limited and the associated features remain poorly defined. To further expand knowledge of ADH2, we aimed to provide detailed clinical, biochemical and radiological characterization of a family with $\mathrm{ADH} 2$ caused by a V340M GNA11 mutation.

\section{Materials and methods}

\section{Subjects}

The index patient, an 11-year-old boy, his three siblings, father, grandfather and father's sister $(n=7)$ were included in the study. All subjects underwent biochemical and genetic evaluation, and clinical data and imaging findings were collected from hospital records. All participants or their guardians gave a written informed consent. The study was approved by the Institutional Research Ethics Board.

\section{Biochemical findings}

Plasma or urine calcium, creatinine, phosphate and alkaline phosphatase were measured by standard methods, and plasma intact PTH was measured by an electrochemiluminescence immunoassay (Roche Diagnostics). Serum 25-hydroxyvitamin D (25(OH)D) was assessed by an electrochemiluminescence binding assay (Roche Diagnostics) and 1,25-dihydroxyvitamin D $\left(1,25(\mathrm{OH})_{2} \mathrm{D}\right)$ by an immunoextraction and competitive luminoimmunologic assay (Immunodiagnostic Systems, Boldon, UK).

\section{Genetic testing}

Genomic DNA was isolated from peripheral blood and Sanger sequenced for the coding exons of GNA11; primer sequences and PCR conditions are given in Supplementary Table 1, see section on supplementary data given at the end of this article. The heterozygous nucleotide change $(\mathrm{G}>\mathrm{A})$, identified in the index patient, introduces a restriction site for the endonuclease NlaIII thus allowing confirmation of the mutation through incubation of the genomic PCR products with this enzyme in the other family members.

\section{Imaging studies}

We collected original skeletal radiographs (including bone age radiographs, $n=9$ ) and brain imaging studies with computed tomography (CT, $n=5)$ and magnetic resonance imaging (MRI, $n=4$ ). All images were re-evaluated by an experienced neuroradiologist. 

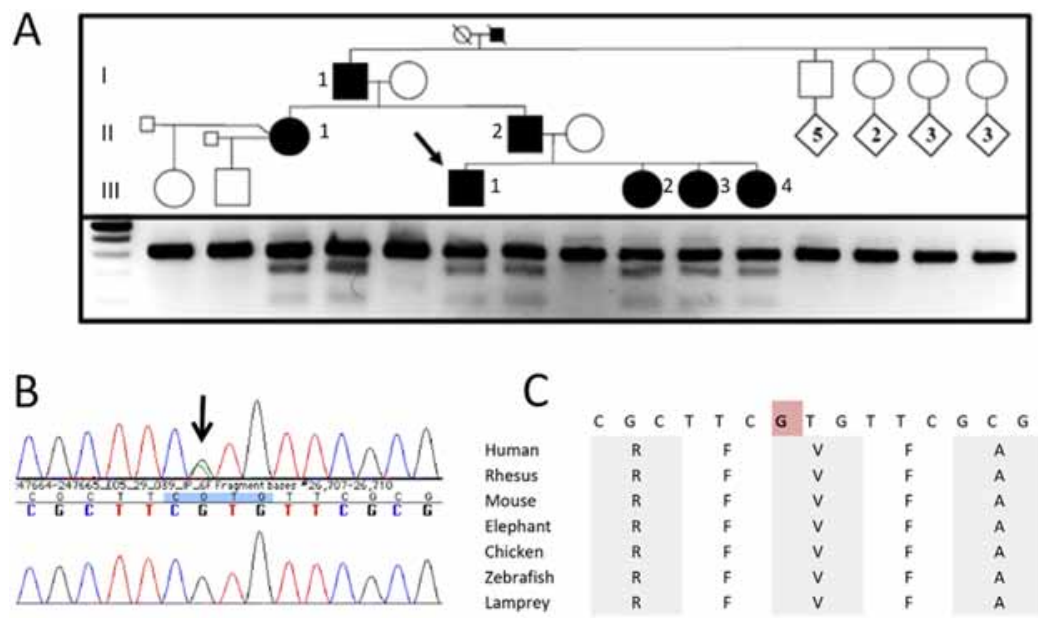

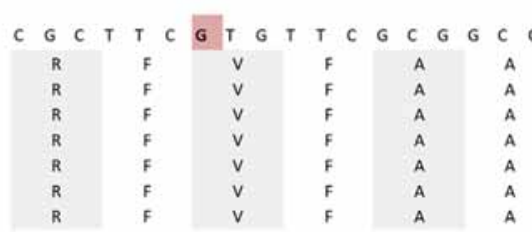

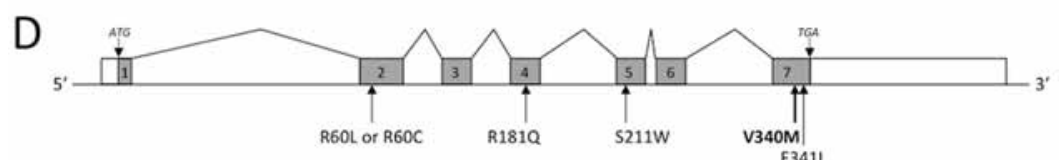

\section{Figure 1}

(A) Pedigree of the family with $A D H 2$. Black symbols indicate affected individuals; the arrow points to the index patient. The G>A mutation in affected individuals introduces a restriction site for the endonuclease N/alll, thus readily allowing assessment of the genotype. Gel electrophoresis and EtBr-staining of PCR-amplified DNA after incubation with N/alll are shown below the pedigree: a single, nondigested DNA band derived from the wild-type allele was observed in mutation-negative individuals, while two additional fragments were identified in patients with the heterozygous c.1018G>A mutation in GNA11. (B) GNA11 sequence in the index patient (upper panel) and in a control sample (lower panel) showing the heterozygous G>A mutation. (C) The mutation changes the highly conserved amino acid valine to methionine at position 340 of $\mathrm{G}_{11}$. (D) Location of the identified mutation in GNA11 exon 7 that introduces the V340M change is adjacent to the previously reported nucleotide change that introduces the F341L substitution. Other previously reported GNA11 mutations that cause ADH2 are located in exons 2, 4 and 5.

\section{Results}

\section{Clinical and biochemical findings}

The index patient III-1 (Fig. 1), a 11-year-old boy, was followed since birth because of hypoparathyroidism in his family. During infancy, his plasma ionized calcium levels were in the low normal range. At the age of 1 year, PTH levels were inappropriately low for his plasma ionized calcium concentration, suggesting hypoparathyroidism, but the child remained asymptomatic (Table 1). Later, asymptomatic hypocalcemia was also established in his three younger siblings at 1-3years of age (Tables 1 and 2). In all these children, plasma PTH concentrations were low for hypocalcemia, plasma phosphate levels normal or mildly elevated compared with age-appropriate reference values; plasma magnesium levels were normal (Table 2).

Table 1 Anthropometric and biochemical characteristics of the affected children with autosomal dominant hypocalcemia in early childhood. Age-appropriate reference ranges of the biochemical parameters are presented in the brackets.

\begin{tabular}{|c|c|c|c|}
\hline \multirow[b]{2}{*}{ Child } & \multicolumn{3}{|c|}{ Anthropometric characteristics at birth } \\
\hline & Weight (g/s.D. score) & Length ( $\mathrm{cm} / \mathrm{s} . \mathrm{D}$. score) & Head circumference (cm/s.D. score) \\
\hline III-1 & $3290 /-1.2$ & $49 /-1.6$ & $33.5 /-1.8$ \\
\hline III-2 & $3265 /-0.8$ & $46 /-2.4$ & $33 /-1.5$ \\
\hline III-3 & $3055 /-1.1$ & $47 /-1.6$ & $33 /-1.4$ \\
\hline III-4 & $3304 /-0.4$ & $48 /-0.9$ & $36 /+1.2$ \\
\hline
\end{tabular}

\begin{tabular}{|c|c|c|}
\hline Ionized Ca (mmol/L) & $\mathrm{Pi}(\mathrm{mmol} / \mathrm{L})$ & PTH (ng/L) \\
\hline 1.09 (1.17-1.35) & $2.13(1.3-2.2)$ & $8.5(9-71)$ \\
\hline 1.18 (1.17-1.35) & $2.04(1.3-2.2)$ & $12.3(9-71)$ \\
\hline 1.05 (1.17-1.35) & $1.97(1.1-1.8)$ & $16.0(12-47)$ \\
\hline 1.08 (1.17-1.35) & $2.10(1.1-1.8)$ & $16.0(12-47)$ \\
\hline
\end{tabular}

Ca, calcium; Pi, inorganic phosphate; PTH, parathyroid hormone. 
Table 2 Biochemical findings of the family members $(n=7)$ with autosomal dominant hypocalcemia at study assessment. Age-appropriate reference ranges of the biochemical parameters are presented in the table.

\begin{tabular}{|c|c|c|c|c|c|c|c|c|c|c|c|}
\hline & $\begin{array}{c}\mathbf{P}-\mathbf{C a} \\
\mathrm{mmol} / \mathrm{L}\end{array}$ & $\begin{array}{c}\text { P-Ca-ion } \\
\mathrm{mmol} / \mathrm{L}\end{array}$ & $\begin{array}{c}\text { P-Pi } \\
\mathrm{mmol} / \mathrm{L}\end{array}$ & $\begin{array}{c}\text { P-Mg } \\
\mathrm{mmol} / \mathrm{L}\end{array}$ & $\begin{array}{c}\text { P-PTH } \\
\mathrm{ng} / \mathrm{L} \\
\end{array}$ & $\begin{array}{c}\text { P-ALP } \\
\text { U/L }\end{array}$ & $\begin{array}{c}\text { S-250HD } \\
\mathrm{nmol} / \mathrm{L}\end{array}$ & $\begin{array}{c}\text { S-1,25(OH) })_{2} \mathbf{D} \\
\mathrm{pmol} / \mathrm{L}\end{array}$ & $\begin{array}{c}\mathbf{P}-\mathbf{C r} \\
\mu \mathrm{mol} / \mathrm{L}\end{array}$ & $\begin{array}{c}\mathbf{d U}-\mathbf{C a} \\
\mathrm{mmol}\end{array}$ & $\begin{array}{c}\text { U-Ca/Cr-ratio } \\
\mathrm{mmol} / \mathrm{L} / \mathrm{mmol} / \mathrm{L}\end{array}$ \\
\hline \multicolumn{12}{|l|}{ Adults/age } \\
\hline Ref range & $2.15-2.51$ & $1.16-1.30$ & $0.71-1.53$ & $0.71-0.94$ & $12-47$ & 35-105 & $>40$ & $63-228$ & $60-100$ & $1.3-6.5$ & \\
\hline I-1/63.6y* & 1.90 & 0.95 & 1.09 & 0.81 & 12.0 & NA & NA & NA & 143 & 5.6 & \\
\hline II-1/45.5y & NA & 0.97 & 1.22 & 0.80 & 12.0 & 70 & 79 & NA & 86 & NA & \\
\hline II-2/37.8y & NA & 1.00 & 1.33 & NA & 13.0 & 80 & 46 & NA & 108 & 3.5 & \\
\hline \multicolumn{12}{|c|}{ Children/age } \\
\hline Ref range & $2.05-2.70$ & $1.16-1.30$ & $1.10-1.80$ & $0.7-1.0$ & $12-47$ & $115-460$ & $>40$ & $63-228$ & $10-76$ & & $<0.6$ \\
\hline III-1/11.0y & 1.95 & 1.02 & 2.27 & 0.77 & 12.0 & 254 & 86 & 120 & 48 & & 0.16 \\
\hline III-2/9.5y & 2.08 & 1.08 & 1.96 & 0.79 & 12.0 & 194 & 82 & 98 & 52 & & 0.18 \\
\hline III-3/5.2y & 1.94 & 1.04 & 2.10 & 0.83 & 19.0 & 212 & 70 & 147 & 33 & & 0.13 \\
\hline III-4/2.8y & 2.14 & 1.14 & 1.80 & 0.87 & 18.0 & 194 & 117 & 166 & 24 & & 0.14 \\
\hline
\end{tabular}

ALP, alkaline phosphatase; Ca, calcium; Cr, creatinine; dU, $24 \mathrm{~h}$ urine; $\mathrm{Mg}$, magnesium; NA, not available; $\mathrm{P}$, plasma; $\mathrm{P}_{\mathrm{i}}$, inorganic phosphate; PTH, parathyroid hormone; S, serum; $U$, urine; 1,25(OH) 2 , 1,25-dihydroxyvitamin $D ; 25 O H D, 25$-hydroxyvitamin D.

*The patient was on alfacalcidol treatment during the evaluation.

Physical examination revealed no abnormalities except a positive Chvostek sign. None of the children had a history of mucocutaneous candidiasis or any clinical sign suggestive for autoimmune polyendocrinopathy syndromes.

Three of these children (III-1, III-3 and III-4) were born at term and had appropriate birth measures; one child (III2) was small for gestational age with a low birth length s.D. score (Table 1). All affected children had their height below -2.0 s.D. scores for the population by 4 years of age. The height S.D. scores of the two unaffected children were -0.5 and -0.5 at the age of 10 and 11 years (Fig. 2). All affected adults were also short (<-2.3 S.D. scores for the population).

The index patient was treated with alfacalcidol and calcium for about 3 years. During the treatment period, his plasma ionized calcium remained slightly subnormal, with urinary calcium/creatinine ratio in the reference range, but inappropriately high for hypocalcemia.

At 25 years of age, the father of these children (II-2, Fig. 1) had experienced mild hypocalcemic symptoms (numbness and tingling), and hypoparathyroidism had been diagnosed. He had been treated with alfacalcidol and calcium, but the medication had been discontinued because of nausea and discomfort. Screening for CASR mutations was negative. Hypoparathyroidism was also diagnosed in the father's sister (II-1, Fig. 1) at 28 years of age. She had several symptoms of hypocalcemia (numbness, tingling, muscle cramps, carpopedal spasms, tremor and seizures). Consequently, their father (I-1, Fig. 1) was screened for hypocalcemia, and he was diagnosed with hypoparathyroidism at 57 years of age. He had had mild hypocalcemic symptoms before the diagnosis, but later he developed severe symptoms, including seizures.

\section{Imaging findings}

Five patients ( 3 adults and 2 children) had altogether five brain-computed tomography (CT) and four magnetic resonance imaging (MRI) scans.

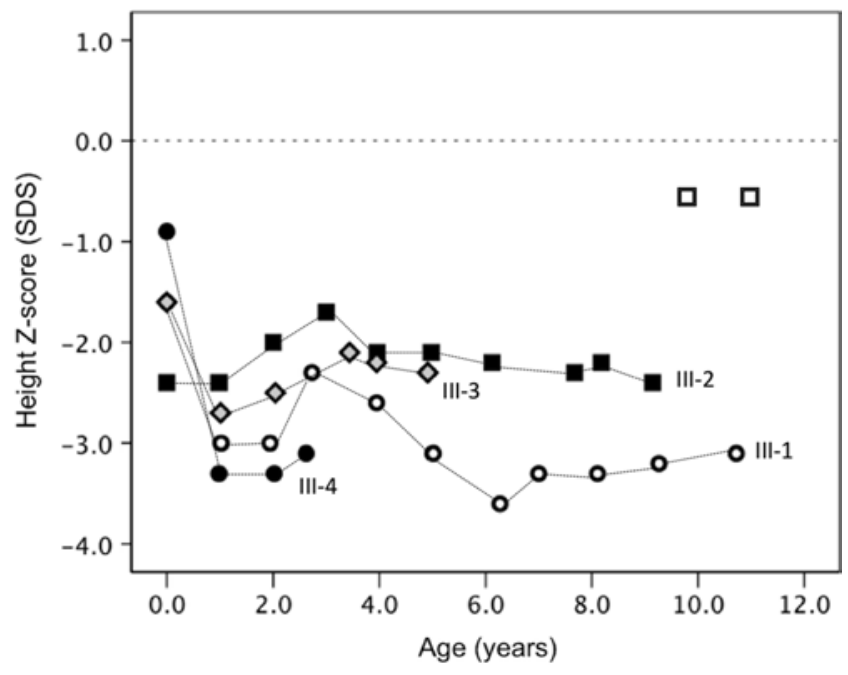

Figure 2

Longitudinal growth during childhood in the four children with $A D H$ due to the V340M GNA11 mutation. Each patient's length/height measurements, transformed into S.D. scores using age- and sex-specific normative data, are shown with different symbols. Height S.D. scores of two mutation-negative siblings are indicated with open squares. The dotted line represents the mean ( 0 s.D. level) of healthy Finnish children. 


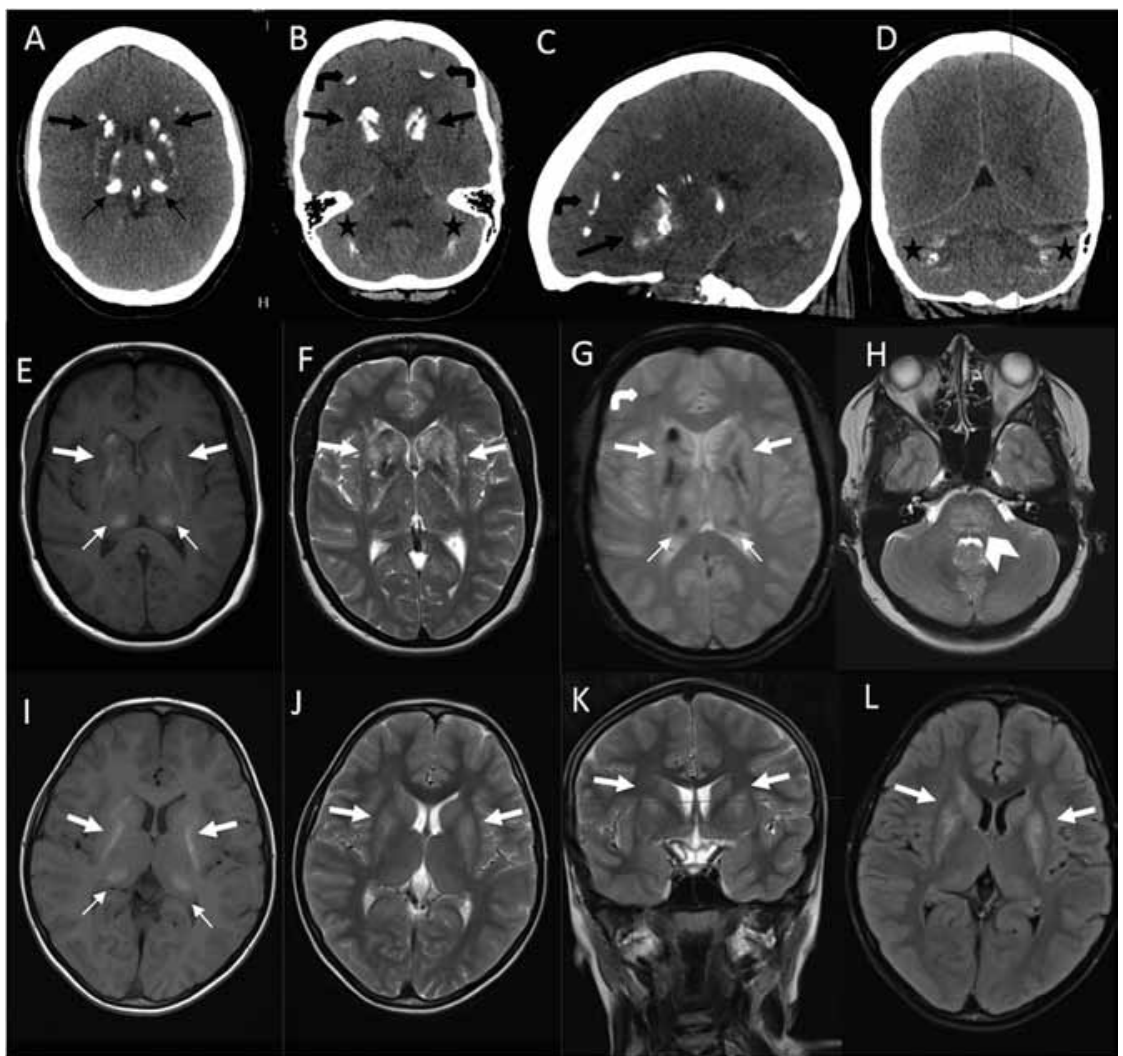

\section{Figure 3}

Characteristic brain imaging findings in two GNA11 mutation-positive individuals. Upper row, ( $, B, C$ and D): In the female patient II-1, a brain CT scan at 45 years of age shows multiple symmetric calcifications in thalamic pulvinar nuclei (thin arrows) and in basal ganglia (thick arrows), in frontal subcortical white matter (curved arrows) and in the cerebellum (asterisks). Middle row, (E, F, G and H): MRI scans of the same patient II-1 demonstrate in a T1-weighted image (E) abnormal high signal intensities in thalamic pulvinar nuclei (thin white arrows), caudate and lentiform nuclei (thick white arrows), and in a T2-weighted image (F) symmetric involvement of the thalamus and basal ganglia with both hyper- and hyposignal areas. A susceptibility-weighted image (G) at the same level shows calcifications as low signal intensity lesions in the thalamus and basal ganglia with a larger calcification in the right caudate nucleus. Small low-intensity calcified foci were noted in the frontal subcortical white matter (curved white arrow) and in the cerebellum (not shown) corresponding calcified lesions seen on CT. In addition, slight hyperintensity of the pons (white arrow head) was noted in a T2-weighted image of the posterior fossa $(\mathrm{H})$. Lower row, $(\mathrm{I}, \mathrm{J}, \mathrm{K}$ and L): MRI of the index patient III-1 at 10 years of age demonstrates similar pattern but considerably less prominent and less calcified changes in the basal ganglia and thalamus than those seen in patient II-1. A similar distribution of symmetric abnormal T1-hypersignalities in thalamic pulvinar nuclei and in basal ganglia, and abnormal T2-hyperintense involvement of the caudate and lentiform nuclei was observed in axial (J) and coronal (K) T2-weighted images and in an axial FLAIR image (L).

At 10years of age, a head MRI scan of the index patient (III-1) revealed signal abnormalities in basal ganglia and thalamus including T1-hypersignal lesions in the pulvinar nuclei and the caudate and lentiform nuclei consistent with calcium accumulation/calcification (Fig. 3). However, the younger sibling (III-2, Fig. 1) had no basal ganglia calcifications at 9 years of age.

In the father (II-2), basal ganglia and thalamic calcifications as well as focal subcortical cerebral and radiating cerebellar calcifications had been found at the time of diagnosis (25years of age) (both CT and MRI scan of the head). The father's sister (II-1) had on her head CT and MRI (at 45 years of age) (Fig. 3) similar thalamic, basal ganglia, subcortical frontal and cerebellar calcifications as his brother did. The head CT scan of the index case's grandfather (I-1) showed only few punctuate calcifications in the basal ganglia (at 72 years of age) (Table 3 ). 
Table 3 Clinical findings of the family members $(n=7)$ with autosomal dominant hypocalcemia.

\begin{tabular}{|c|c|c|c|c|c|c|c|c|}
\hline & Sex & $\begin{array}{c}\text { Age at } \\
\text { hypocalcemia } \\
\text { diagnosis } \\
\text { (years) }\end{array}$ & $\begin{array}{l}\text { Symptoms of } \\
\text { hypocalcemia }\end{array}$ & Height* $(\mathrm{cm})$ & $\begin{array}{c}\text { Height } \\
\text { (s.D. score) }\end{array}$ & $\begin{array}{l}\text { Basal ganglia } \\
\text { calcifications/age } \\
\text { (years) at the } \\
\text { examination }\end{array}$ & Nephro calcinosis & Medication \\
\hline \multicolumn{9}{|l|}{ Adults } \\
\hline I-1 & $\mathrm{M}$ & 57 & Yes & 162.0 & -3.0 & $(+) / 72$ & No & $\begin{array}{l}\text { Alfacalcidol, } \\
\text { calcium }\end{array}$ \\
\hline II-1 & $\mathrm{F}$ & 28 & Yes & 155.0 & -2.3 & $+++/ 45$ & No & $\begin{array}{l}\text { Alfacalcidol, } \\
\text { calcium, } \\
\text { discontinued }\end{array}$ \\
\hline II-2 & $\mathrm{M}$ & 25 & Yes & 160.0 & -3.4 & $++/ 25$ & No & $\begin{array}{l}\text { Alfacalcidol, } \\
\text { calcium, } \\
\text { discontinued }\end{array}$ \\
\hline \multicolumn{9}{|c|}{ Children } \\
\hline III-1 & $\mathrm{M}$ & 1 & No & $125.9 / 10.7$ years & -3.1 & $+/ 10$ & No & $\begin{array}{l}\text { Alfacalcidol, } \\
\text { calcium, } \\
\text { discontinued }\end{array}$ \\
\hline III-2 & $\mathrm{F}$ & 3 & No & $121.8 / 9.1$ years & -2.4 & -19 & No & No \\
\hline III-3 & $\mathrm{F}$ & 1 & No & $100.4 / 4.9$ years & -2.3 & NA & No & No \\
\hline III-4 & $\mathrm{F}$ & 2 & No & 83.0/2.6years & -3.1 & NA & No & No \\
\hline
\end{tabular}

$\mathrm{F}$, female; height, adult height or height at the examination; $\mathrm{M}$, male; NA, not available.

*Data for children is presented as Height/age. - , no; $(+)$, minimal; +, mild; ++, moderate; +++, abundant.

None of the affected family members had nephrocalcinosis. However, two of the adult subjects had slightly elevated plasma creatinine levels of unknown etiology (Table 2).

Bone age radiographs $(n=9)$, available for four children, showed normal skeletal maturation. Further, the metaphyseal and epiphyseal development was normal, as were the shape and relative lengths of the metacarpals and phalanges.

\section{Genetic findings}

Sanger sequencing revealed in all seven hypocalcemic subjects, but not in the healthy family members $(n=4)$, a heterozygous GNA11 missense mutation c.1018G $>$ A, p.V340M (Fig. 1). The mutation is located adjacent to a mutation (F341L) that was previously identified in affected members of another family with autosomal dominant hypoparathyroidism (Fig. 1D) (4) and affects an amino acid residue that is strictly conserved in mammals, chicken, zebrafish and lamprey (UCSC Genome Database) (Fig. 1C).

\section{Discussion}

In this study, we identified in a family with seven members affected by $\mathrm{ADH}$, but without CASR mutations, a heterozygous GNA11 missense mutation that changes amino acid residue 340 from valine to methionine (V340M). Our patients with the GNA11 mutation showed common biochemical features of $\mathrm{ADH}$, similar to those in the recently described subjects with $\mathrm{ADH}$ and GNA11 mutations (4, 8, $13,14)$. The adult patients had symptomatic hypocalcemia, whereas the children were asymptomatic. Calcifications in the central nervous system were found in more than $50 \%$ of the family members.

To date, only five different heterozygous missense GNA11 mutations in patients with AHD (without CASR mutations) have been reported $(4,8,13)$. The affected subjects were hypocalcemic, had low or normal serum PTH and normal or high serum phosphate concentrations (4). Nesbit et al. (4) and Li et al. (13) reported that patients with $\mathrm{ADH}$ due to GNA11 mutations did not have hypercalciuria, which is observed in about $10 \%$ of patients with ADH1 (4). Our patients had their urinary calcium excretion in the reference range, being inappropriately high for hypocalcemia. Furthermore, they lacked hypomagnesemia similarly to the recently reported patients with activating GNA11 mutations $(8,13)$.

Recently, Thim et al. reviewed the pediatric presentation of $\mathrm{ADH}$ caused by activating variants in the CASR gene (12). They analyzed the data of 48 pediatric ADH1 patients. More than $50 \%$ of the patients had had severe neurological symptoms, and 25\% were asymptomatic. The severity of the neurological symptoms was related inversely to serum calcium concentrations 
but not to age (12). Similarly, in an adult population, the occurrence of hypocalcemic symptoms was related to the degree of hypocalcemia (11).

In this study, four of the five family members who were examined by MRI or CT had detectable intracranial calcifications. The youngest subject was 10 years old at the time of detecting the intracranial calcifications. On the contrary, the oldest family member had only minimal calcifications at 72 years of age indicating a poor genotypephenotype correlation in terms of central nervous system calcifications. The occurrence of intracranial or renal calcifications was not associated with the severity of hypocalcemia at the age of diagnosis in the previously mentioned study concerning ADH1 (11). In our patients with $\mathrm{ADH} 2$, intracranial calcifications appeared not only in the basal ganglia but also elsewhere in the central nervous system.

In the current study, the affected subjects were short. All four affected children had their birth weights appropriate for gestational age, and only one was born short for gestational age ( -2.4 s.D. scores), suggesting that intrauterine growth is not likely to be impaired. However, postnatal linear growth decelerated already in infancy and all of them grew below the -2.0 s.D. level at the examination. The three affected adults in our family were also short. Recently, Li et al. reported that subjects with GNA11 mutations were shorter than their unaffected family members without evidence of growth hormone deficiency (13). Short stature is not a typical feature of ADH caused by CASR mutations. However, one study reported four family members in three generations with $\mathrm{ADH}$ and a possible CASR mutation having short stature and premature osteoarthritis (14). The mechanism linking activating GNA11 mutations to short stature is not yet determined. In epiphyseal chondrocyte differentiation, the $\alpha$-subunit of the stimulatory G-protein $\left(\mathrm{G} \alpha_{s}\right)$ (among all G-proteins expressed in chondrocytes) seems to have the most important role (reviewed in 15). Thus signaling through $\mathrm{G \alpha}_{\mathrm{s}}$, the major second messenger pathway activated by PTHR1, prevents premature chondrocyte differentiation. Ablation of either $G \alpha_{s}$ or PTHR1 leads to accelerated chondrocyte differentiation, and thus premature fusion of the growth plate postnatally and short stature. The role of $\mathrm{G} \alpha_{\mathrm{q} / 11}$ in chondrocyte differentiation is little known. To date, there are no experiments describing the genetic ablation or overexpression of either $G \alpha_{q}$ or $\mathrm{G} \alpha_{11}$ in chondrocytes. Accordingly, it cannot be excluded that activation or inactivation of $\mathrm{G} \alpha_{\mathrm{q} / 11}$ could impact chondrocyte differentiation (15). The findings in our study and those of Li et al. (13) support the hypothesis that short stature may be a consequence of increased $\mathrm{G} \alpha_{11}$ signaling in patients with ADH caused by GNA11 mutations.

The identified GNA11 mutation results in biochemical abnormalities typical for ADH. Additional features, including short stature and early basal ganglia calcifications and more widespread intracranial calcifications, cosegregated with the mutation. Our findings indicate a wider role for $\mathrm{G} \alpha_{11}$ signaling besides calcium regulation.

\section{Supplementary data}

This is linked to the online version of the paper at http://dx.doi.org/10.1530/ EJE-16-0109.

\section{Declaration of interest}

The authors declare that there is no conflict of interest that could be perceived as prejudicing the impartiality of the research reported.

\section{Funding}

This study was financially supported by Kuopio University Hospital, the Academy of Finland, the Sigrid Jusélius Foundation, the Folkhälsan Research Foundation, Foundation for Pediatric Research, the Novo Nordisk Foundation, the Helsinki University Hospital research funds, the Swedish Research Council, the Swedish Childhood Cancer Foundation, through the regional agreement on medical training and clinical research (ALF) between Stockholm County Council and Karolinska Institutet, and through NIDDK grants to H J (R01DK46718-20 and PO1DK11794 (subproject IV)).

\section{Author contribution statement}

Study design: S T, R V and O M. Study conduct: S T, R V, H J and O M. Data collection: S T, R V, M R, S T-S, H J and O M. Data analysis: S T, R V, M R, S T-S, H J and O M. Data interpretation: S T, S T-S, H J and O M. Drafting manuscript: S T, S T-S and O M. Revising manuscript content: S T, R V, S T-S, $\mathrm{H} J$ and $\mathrm{O} M$. Approving final version of manuscript: S T, R V, M R, S T-S, $\mathrm{H} \mathrm{J}$ and $\mathrm{O} M$ M. S T, R V, M R, S T-S, H J and O M take responsibility for the integrity of the data analysis.

\section{References}

1 Pearce SH, Williamson C, Kifor O, Bai M, Coulthard MG, Davies M, Lewis-Barned N, McCredie D, Powell H, Kendall-Taylor P et al. A familial syndrome of hypocalcemia with hypercalciuria due to mutations in the calcium-sensing receptor. New England Journal of Medicine 1996335 1115-1122. (doi:10.1056/nejm199610103351505)

2 Thakker RV. Diseases associated with the extracellular calciumsensing receptor. Cell Calcium 200435 275-282. (doi:10.1016/j. ceca.2003.10.010)

3 Nesbit MA, Hannan FM, Graham U, Whyte MP, Morrison PJ, Hunter SJ \& Thakker RJ. Identification of a second kindred with familial hypocalciuric hypercalcemia type 3 (FHH3) narrows localization to a $<3.5$ megabase pair region on chromosome $19 \mathrm{q} 13.3$. Journal of Clinical Endocrinology and Metabolism 201095 1947-1954. (doi:10.1210/jc.2009-2152)

4 Nesbit MA, Hannan FM, Howles SA, Babinsky VN, Head RA, Cranston T, Rust N, Hobbs MR, Heath H 3rd \& Thakker RV Mutations affecting G-protein subunit $\alpha_{11}$ in hypercalcemia and hypocalcemia. 
New England Journal of Medicine 2013368 2476-2486. (doi:10.1056/ NEJMoa1300253)

5 Nesbit MA, Hannan FM, Howles SA, Reed AA, Cranston T, Thakker CE, Gregory L, Rimmer AJ, Rust N, Graham U et al. Mutations in AP2S1 cause familial hypocalciuric hypercalcemia type 3. Nature Genetics 201345 93-97. (doi:10.1038/ng.2492)

6 Tenhola S, Hendy GN, Valta H, Canaff L, Lee BS, Wong BY, Välimäki MJ, Cole DE \& Mäkitie O. Cinacalcet treatment in an adolescent with concurrent 22q11.2 deletion syndrome and familial hypocalciuric hypercalcemia type 3 caused by AP2S1 mutation. Journal of Clinical Endocrinology and Metabolism 2015100 2515-2518. (doi:10.1210/jc.2015-1518)

7 Pollak MR, Brown EM, Estep HL, McLaine PN, Kifor O, Park J, Hebert SC, Seidman CE \& Seidman JG. Autosomal dominant hypocalcaemia caused by a $\mathrm{Ca}^{2+}$-sensing receptor gene mutation. Nature Genetics 19948 303-307. (doi:10.1038/ng1194-303)

8 Mannstadt M, Harris M, Bravenboer B, Chitturi S, Dreijerink KM, Lambright DG, Lim ET, Daly MJ, Gabriel S \& Jüppner H. Germline mutations affecting $\mathrm{G} \alpha_{11}$ in hypoparathyroidism. New England Journal of Medicine 2013368 2532-2534. (doi:10.1056/NEJMc1300278)

9 Lambert AS, Grybek V, Francou B, Esterle L, Bertrand G, Bouligand J, Guiochon-Mantel A, Hieronimus S, Voitel D, Soskin S et al. Analysis of AP2S1, a calcium-sensing receptor regulator, in familial and sporadic isolated hypoparathyroidism. Journal of Clinical Endocrinology and Metabolism 201499 E469-E473. (doi:10.1210/jc.2013-3136)

10 Rogers A, Nesbit MA, Hannan FM, Howles SA, Gorvin CM, Cranston T, Allgrove J, Bevan JS, Bano G, Brain C et al. Mutational analysis of the adaptor protein 2 sigma subunit (AP2S1) gene: search for autosomal dominant hypocalcemia type 3 (ADH3). Journal of Clinical Endocrinology and Metabolism 201499 E1300-E1305. (doi:10.1210/jc.2013-3909)

11 Raue F, Pichl J, Dörr HG, Schnabel D, Heidemann P, Hammersen G, Jaursch-Hancke C, Santen R, Schöfl C, Wabitsch M et al. Activating mutations in the calcium-sensing receptor: genetic and clinical spectrum in 25 patients with autosomal dominant hypocalcemia - a German survey. Clinical Endocrinology 201175 760-765. (doi:10.1111/ j.1365-2265.2011.04142.x)

12 Thim SB, Birkebaek NH, Nissen PH \& Høst C. Activating calciumsensing receptor gene variants in children: a case study of infant hypocalcaemia and literature review. Acta Paediatrica 2014103 1117-1125. (doi:10.1111/apa.12743)

13 Li D, Opas EE, Tuluc F, Metzger DL, Hou C, Hakonarson H \& Levine MA. Autosomal dominant hypoparathyroidism caused by germline mutation in GNA11: phenotypic and molecular characterization. Journal of Clinical Endocrinology and Metabolism 2014 99 E1774-E1783. (doi:10.1210/jc.2014-1029)

14 Stock JL, Brown RS, Baron J, Coderre JA, Mancilla E, De Luca F, Ray K \& Mericq MV. Autosomal dominant hypoparathyroidism associated with short stature and premature osteoarthritis. Journal of Clinical Endocrinology and Metabolism 199984 3036-3040. (doi:10.1210/ jc.84.9.3036)

15 Chagin AS \& Kronenberg HM. Role of G-proteins in the differentiation of epiphyseal chondrocytes. Journal of Molecular Endocrinology 201453 R39-R45. (doi:10.1530/JME-14-0093)

Received 6 February 2016

Revised version received 21 April 2016

Accepted 17 June 2016 